\title{
Managerial Characteristics as Drivers of Innovation
}

\author{
Derrick Bonyuet ${ }^{1,2}$ \\ ${ }^{1}$ Spears School of Business, Oklahoma State University, Stillwater, USA \\ ${ }^{2}$ School of Business and Technology, Huston-Tillotson University, Austin, USA \\ Correspondence: Derrick Bonyuet, School of Business and Technology, Huston-Tillotson University, 14812 Haley \\ Hollow, Austin, TX 78728. USA. Tel: 1-512-728-2317.
}

Received: December 29, 2020

Accepted: February 13, 2021

Online Published: March 18, 2021

doi:10.5430/ijfr.v12n4p24

URL: https://doi.org/10.5430/ijfr.v12n4p24

\begin{abstract}
Plenty of powerful and promising companies have failed in the history of Corporate America. While many factors may have contributed to this outcome, lack of innovation is often one of the factors highlighted. After all, innovation, which can be defined as the successful exploitation of new ideas (Nathan \& Lee, 2013), has been found to be a strong predictor of a firm's future returns. However, what drives the creation of successful corporate innovation is not yet fully understood. On this study, I want to focus on managerial characteristics and how such diversity attributes can drive innovation. Joshi \& Jackson (2003) define diversity as "the distribution of personal attributes among interdependent members of a work unit." The combination of these diversity attributes can generate ideas and fresh perspectives feeding the creativity process which in turn will result in innovation. The diversity attributes at the managerial level are critical as the top management team (TMT) has the ability to define the direction of the firm. The purpose of this study is to assess whether diverse managerial characteristics at the TMT level drives firm innovation. This research question is tested using a sample of S\&P 500 firms over the period 2010-2017. Innovation is measured by patent filings and citations. The empirical results show diversity traits such as tenure, culture, education and political affiliation do positively influence innovation. Gender, age and job diversity were found not to be significant.
\end{abstract}

Keywords: innovation, managerial characteristics, diversity, top management

We're supposed to be bringing out-of-the box thinking and innovation, and you cannot do that unless you got diversity.

Julie Sweet, Accenture CEO

\section{Introduction}

We have seen over the last two decades how powerful companies, such as Blockbuster Video, Blackberry and Polaroid, once seen as corporate icons, have shut down due to their lack of innovation (Goh, 2014). As a result, researchers in different disciplines such as management and financial economics, have started to study innovation as a phenomenon. After all, innovation represents approximately $50 \%$ of a country's total GDP growth and economists have estimated $85 \%$ of a nation's economic growth is due to technological innovation (He \& Tian, 2018). At the firm level, firms that exhibit higher innovative activity tend to have on average higher subsequent market valuations and superior future operating performance and stock returns (Hirshleifer, Hsu and Li, 2013). As a result, many scholars have been attempting to understand what drives innovation. Innovation, which can be defined broadly as the successful exploitation of new ideas (Nathan \& Lee, 2013), can be influenced by many different factors, such as development costs, new product complexity, creativity, risk tolerance and regulatory environment. However, one area that is being explored corresponds to the personal attributes exhibited by members of the top management team (TMT). Such personal attributes may include diversity traits such as age, gender and ethnicity among many others. According to Joshi and Jackson (2003), diversity can be defined as "the distribution of personal attributes among interdependent members of a work unit." As diversity propels ideas and perspectives from different people, the creativity process is energized and thus, innovation rises. Assessing the impact of diversity at the top management team (TMT) level is critical given the ability of this group to define the direction of the firm. Finkelstein, Hambrick and Cannella (2009) define TMT as a relatively small group of individuals at the top of an organization, such as the CEO and those who report directly to him or her. TMT members can encourage employees to think creatively and even set corporate policies and compensation schemes to support the development of new ideas. Pro-diversity 
policies have been found to enhance a firm's ability to innovate (Mayer, Warr \& Zhao, 2018). Likewise, a firm's innovative activity has been found to be positively related to managers' incentive compensation plan (Baranchuk, Kieschnick and Moussawi, 2013). Furthermore, when an individual in a team shares a common trait with the end user, the entire team better understands the end user. As a result, those firms with a diverse leadership can out-innovate and out-perform others (Hewlett, Marshall \& Sherbin, 2013). The purpose of this study is to assess whether diverse managerial characteristics at the top management team level drives firm innovation.

This study contributes to the existing literature in two different dimensions. First, it expands the scope of participants under study to include not only the CEO but also other members of the top management team. Secondly, it further explores the impact of a wide array of personal attributes, such as age, gender, tenure, cultural background, educational level and political affiliation. By conducting a more comprehensive study, findings will provide a better view of how personal attributes of members from the top management team impact a firm's innovative output.

\section{Literature Review}

A survey of the finance literature on corporate innovation reveals that 68 studies on innovation have been published between 2000 and the third quarter of 2017. Out of the 68 publications, only seven studies relate to personal attributes, such as managerial overconfidence, risk taking personality, skill set, network connections and management quality and, only one focus on the top management team as the unit of analysis. The survey also reveals an increasing trend on the number of innovation studies published on finance journals (He \& Tian, 2018). As a result, this paper contributes to expand our knowledge on the impact of diversity traits at the top management level and firm innovation.

Galasso \& Simcoe (2011) studied the impact of overconfidence, which is a personal attribute characterized by individuals' overestimating their actual abilities, performance, level of control or chance of success (Moore \& Healy, 2008). The impact of this personal attribute on firm innovation was based on the in-the money stock options hold by CEOs after they are fully vested. The authors find a positive association between overconfidence and citation-weighted patents counts with this effect being stronger in more competitive industries. Then, a more comprehensive studied was conducted by Hirshleifer, Low \& Teoh (2012) who examined a larger sample and found consistent results using similar approach as well as a press-based coverage approach where press releases referencing CEOs along words related to their overconfidence were examined.

Sunder, Sunder and Zhang (2017) studied the impact on firm innovation from sensation seeking, which is a personality trait characterized by "the seeking of varied, novel, complex, and intense sensations and experiences, and the willingness to take physical, social, legal, and financial risks for the sake of such experience" (Zuckerman, 2007, p.49). The authors find sensation seeking, which was tested through participants' hobby of flying airplanes, to be associated to a greater innovative output.

The impact of a CEO's skill set along other personal attributes on firm innovation was examined by Custodio, Ferreira and Matos (2019). The authors find general managerial skills are more likely to promote innovation as these skills have gained from different domains, which them enable executives to be more resilient to project failures as they have skills that can be applied elsewhere. Likewise, a CEO's personal network may serve to relieve any risk aversion towards investment decisions resulting in greater innovation ventures. Faleye, Kovacs and Venkateswaran (2015) find CEO connections are positively related to firm innovation with an interquartile change in CEO connection resulting in increases of $9.7 \%$ in R\&D investment rate, $11 \%$ in patents granted and $4 \%$ in citations per patent.

The effectiveness of a firm's top management team may determine its long-term success especially when managing risky and innovative projects. Chemmanur, Kong, Krishnan and Yu (2019) measure the human capital of a firm's top management team using a "management quality factor" based on seven attributes: size of the management team, fraction of managers with MBA or doctoral degrees, fraction of members with prior work experience in the top management team, average number of prior board positions that each manager has served on, and the average employment- and education-based connections of each manager on the management team. The authors find that firms with higher quality management teams show greater R\&D investment and larger innovation output.

While a variety of research has been conducted to assess the relation between innovation and managerial characteristics, there is still an opportunity for better understanding these two variables. First, managerial characteristics researched in the studies above include overconfidence, sensation seeking, managerial skills, personal connections, size of the management team, education, and board experience. However, managerial characteristics are based on personal attributes that vary from one person to another. This is where attributes such as political affiliation, tenure and culture among others are the basis of study for this paper. Secondly, patents are the most important 
measure of contemporary firms' innovative output as numerous studies have used patent data as a proxy for innovation (Mayer, et al, 2018; Sunder, et al, 2017; Chang, et al, 2015; Baranchuk, et al, 2013; Hirshleifer, et al, 2012, 2013). Patents also provide insights in a firm's long-run inventive ability (Griliches, Pakes \& Hall, 1988). Therefore, my study will address these limitations on the existing literature and provide different insights into other managerial characteristics that well may influence firm innovation.

\section{Theory and Hypothesis Development}

Upper echelons theory states managers' strategic decisions may be influenced by their individual characteristics and these strategic decisions will influence firm performance (Hambrick \& Mason, 1984). Different models of decision-making process explain managers may arrive to a different understanding based on the information provided (Daft \& Weick, 1984; Nutt, 1984; Van de Ven \& Ferry, 1980) and as a result, the team composition may influence the number, variety and quality of solutions to be considered (Bantel \& Jackson, 1989). Then, the relationship between team composition and innovation can be analyzed from two different views. First, the psychological view, which is based on the role of cognitive resources in group problem solving. This view states that groups consisting of people with a greater level of knowledge, a variety of skills and ability perform better than groups with lower level of these resources when dealing with complex problems where creativity is required. The second view is derived from the organization demography literature, which is based on the impact of team heterogeneity in organizational processes. This view states that organizations benefit from team diversity when facing complex problems (Bantel \& Jackson, 1989). A key assumption on this study is that a balance on the variety of diversity attributes among TMT members will ensure different perspectives can be brought into the innovation process as these individuals have been exposed to different social, political and economic events, which in turn have shaped their attitudes, beliefs and values (Bantel \& Jackson, 1989). As a result, my main hypothesis comes as follows:

H1: There is a positive relation between TMT diversity and firm innovation

\section{Methods}

\subsection{Data and Sample}

The population for this study includes large firms in the S\&P 500 industrial index for the period 2010 to 2017. Members of the top management team were extracted from the ExecuComp database, which provides company name, company ID (GVKEY), executives' names, title, age, gender and compensation rank among other datapoints. The sample was restricted to the top five executives based on their compensation ranking. Then, a manual search was conducted in the BoardEx database to extract additional measures for each executive related to work experience and educational background. Cultural diversity was proxied based on the country where the executive attended to earn his or her bachelor's degree. Next, information on each executive's political contributions were extracted from the Federal Election Committee (FEC) database to determine their political affiliation. Firm-level accounting variables, such as cash, property, plant \& equipment, total assets, and total debt were extracted from Compustat.

Data on patent and as well as patent citations were extracted from the database available at the US Patent and Trademark Office (USPTO). When examining patents, there are two important dates to consider: the patent application year and the grant year. The former is the most relevant date for the purposes of this study because it is closely related to the time the actual innovation is made. Patent data are subject to two types of truncation biases. First, there is, in average, two-year lag between a patent's application date and grant date. Because patents are included in the database only if they are granted, those patents that were applied for but still under review by 2017 are missed from the data. The second truncation bias affects citations as those patents granted in the later years of the sample will have less time to accumulate citations. As a result, to address this truncation bias, patent counts are multiplied by a weighting index based on the application-grant empirical distribution. Citation counts are adjusted with a weighting index determined through a quasi-structural approach based on the shape of the citation-lag distribution (Hall, Jaffe \& Trajtenberg, 2005).

\subsection{Study Design}

To test the effects of TMT diversity on firm innovation, the following multivariate regression analysis is used:

$$
\text { Firm Innovation }_{\mathrm{i}, \mathrm{t}}=\propto_{0}+\sum_{\mathrm{j}=1}^{\mathrm{n}} \beta_{\mathrm{j}} \text { TMT Diversity }_{\mathrm{j}, \mathrm{i}, \mathrm{t}}+\sum_{\mathrm{k}=1}^{\mathrm{m}} \gamma_{\mathrm{k}} \mathrm{X}_{\mathrm{k}, \mathrm{i}, \mathrm{t}}+\varepsilon_{\mathrm{i}, \mathrm{t}}
$$

Where the dependent variable refers to the measure of innovation of firm $i$ at time t. Patents and citations are scaled as described earlier providing two innovation measures so that two models could be run for robustness and 
confidence. The independent variables consist of seven diversity attributes (TMT Diversity $\left.{ }_{j, i, t}\right)$ indexed by $j$ and measured for firm $\mathrm{i}$ at time $\mathrm{t}$; and the vector of the control variables $\left(X_{k, i, t}\right)$ and $\varepsilon$ is the error term. Similar equation has been used in previous studies (Sunder, Sunder \& Zhang, 2017; Chang, Fu, Low \& Zhang, 2015).

TMT diversity is measured by using the Herfindahl-Hirschman Index (Blau, 1977), which has been used consistently in numerous diversity studies (Talke et al, 2010 and 2011; Bantel \& Jackson, 1989; Nielsen \& Nielsen, 2013; Carpenter, 2002). This index is determined as:

$$
\mathrm{B}=1-\sum\left(\mathrm{P}_{\mathrm{i}}\right)^{2}
$$

where $\mathrm{P}_{\mathrm{i}}$ is the percentage of individuals in the $i^{\text {th }}$ category with the higher the score, the greater TMT diversity on that specific attribute (Carpenter, 2002). The theoretical maximum value of Blau's index can be computed as (i-1)/i where i represents the number of categorical variables. A standardized version of the Blau's index that ranges from 0 to 1, regardless of the number of categories, is obtained by dividing the Blau's index by the theoretical maximum value (Teachman, 1980; Agresti \& Agresti, 1978). Continuous variables, such as age, tenure and job diversity, were classified in cohorts to enable the application of the Blau index.

Numerous control variables have been included such as firm size (natural logarithm of total assets); capital intensity (ratio of net property, plant and equipment to the number of employees); cash holdings (cash-to-asset ratio) and leverage (debt-to-asset ratio). In addition, industry growth rate has been incorporated into the model as industry life cycle may impact the level of innovation in some industries. All control and diversity variables are lagged by one year. Panel regression methodology is used to estimate the regression equation.

\subsection{Summary Statistics}

Table 1 provides information on diversity attributes for the sample of members from the top management team. Over $90 \%$ of the executives are male and over $50 \%$ are 50 to 60 years old. Over 50\% hold master's degree and the great majority, over 90\%, are from English-speaking countries. Table 2 shows the distribution of patents across industries. Over $47 \%$ of the patents are generated by the electrical, electronic, computer and industrial equipment industry followed by the finance, insurance and real estate industry which generates $32 \%$ of the patents. Public administration and the oil and chemical industry follow with $6 \%$ each.

Table 1. Diversity attributes

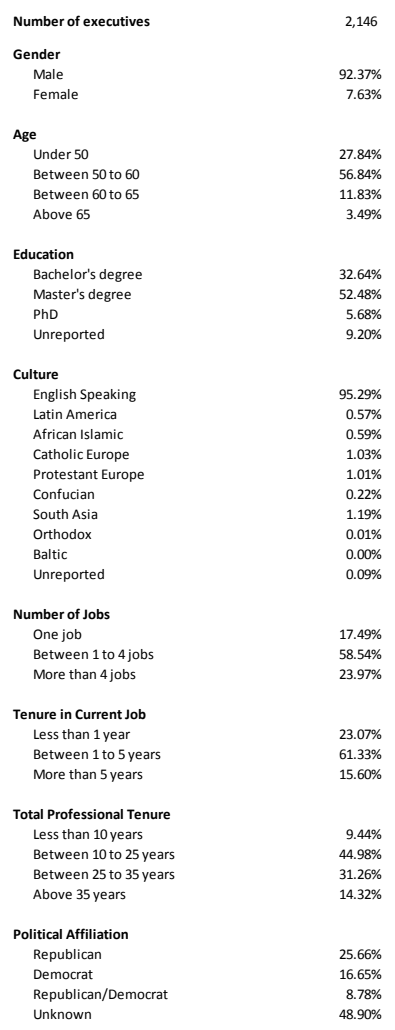

Note: This table reports the diversity attributes from the sample of the study over 2010-2017. 
Table 2. Classification of patent by industry

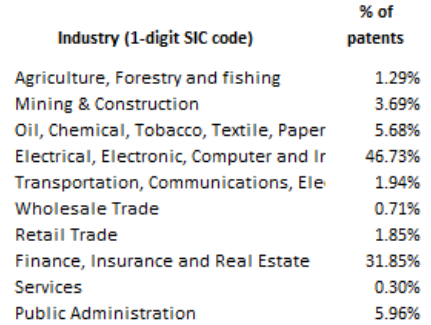

Note: This table shows the distribution by industry of the patents for the sample under study.

Table 3 reports descriptive statistics, including means, medians and standard deviations of the variables used in this study. At the firm-year level, an average firm has 52,000 employees; has book value of assets of $\$ 65,010$ million; sales of $\$ 21,761$ million; invests $\$ 20,000$ on R\&D for every million of assets; capital intensity of 0.528 , which means companies in average hold $\$ 528,000$ in property, plant \& equipment per employee; cash holdings of 0.13 , which means in average companies hold $\$ 130,000$ in cash \& short-term equivalents for every million of assets, leverage of $27 \%$ and ROA of $14 \%$. A firm, on average, generates 69 patents a year and 2 patents per 1000 employees and these patents receive 329 citations in all and 4 citations per 1000 employees. Patent and citation counts follow a non-normal distribution with the presence of high skewness as over $50 \%$ of the firms apply for no patents and therefore, do not receive any citations. As a result, the median number of patent and citation counts is almost zero. To address the lack of normality, innovation variables have been transformed using the natural logarithm of one plus either patent or citation corrected count (Brooks, 2014). Finally, to minimize the effect of outliers, dependent variables are winsorized at the $1^{\text {st }}$ and $99^{\text {th }}$ percentiles. Another issue that is common when dealing with panel data is heteroscedasticity, which is the non-constant variability of the error term over time. As a result, the reliability of the model is impacted. To address heteroscedasticity, robust standard errors are used in the panel data regression and thus, the regression model becomes more homoscedastic (Brooks, 2014).

Table 3. Summary statistics

\begin{tabular}{lcrrrrr}
\multicolumn{1}{c}{ Variable } & Obs & Mean & Median & Std. Dev. & Min & Max \\
\hline Number of patents (raw) & 3,059 & 69 & 1 & 339 & 0 & 7,652 \\
Number of citations (raw) & 3,059 & 329 & 0.0 & 1,639 & 0 & 25,706 \\
Scaled patents/employee & 3,053 & 2 & 0.0 & 8 & 0 & 98 \\
Scaled citations/employee & 3,053 & 4 & 0.0 & 12 & 0 & 189 \\
Assets (Smillions) & 3,059 & 65,010 & 15,855 & 213,680 & 254 & $2,573,126$ \\
Sales (Smillions) & 3,059 & 21,761 & 8,521 & 41,128 & 94 & 483,521 \\
R\&D-to-Assets & 3,059 & 0.02 & 0 & 0.05 & 0 & 0.64 \\
Employees (in thousands) & 3,053 & 52 & 18.50 & 127 & 0.08 & 2,300 \\
Capital Intensity & 2,873 & 0.53 & 0.07 & 1.35 & 0.00 & 12.17 \\
Cash Holdings & 3,059 & 0.13 & 0.08 & 0.14 & 0 & 0.91 \\
Book Leverage & 3,048 & 0.27 & 0.25 & 0.18 & 0 & 1.67 \\
ROA & 2,890 & 0.14 & 0.13 & 0.10 & $(1.16)$ & 0.95
\end{tabular}

Note: This table presents summary statistics for the sample under study of US firms from 2010 to 2017.

A correlation matrix is presented in Table 4. Correlations among the diversity measures are low indicating each of these variables are not necessarily addressing the same dimension. The highest correlation among the diversity variables is .084 between Total Tenure and Job diversity. A high correlation between two or more independent variables may indicate multicollinearity issues, which would then make hard to determine the relative degree of impact of each independent variable on the dependent variable (Blalock, 1963). Pairwise correlation coefficients above $|0.8|$ would indicate the presence of multicollinearity (Gujarati, 2003, p.387). As shown in table 4, none of the independent variables or control variables reflect a correlation coefficient above $|0.8|$. In addition, variance inflation factors were calculated resulting in a VIF of 1.06 which is less than the threshold of 2 indicating not severe multicollinearity issues (Chang, Fu, Low \& Zhang, 2015). With respect to innovation variables, as expected, correlations between patents, citations and R\&D is high. Table 4 shows a correlation of 0.949 between patents and citations and then, 0.446 and 0.430 between patents and $R \& D$ and citations and $R \& D$ respectively. In addition, the presence of positive and significant correlation between innovation measures and diversity measures indicates some degree of association between these variables (Rumsey, 2010). 
Table 4. Correlation matrix

\begin{tabular}{|c|c|c|c|c|c|c|c|c|c|c|c|c|c|c|c|c|}
\hline Variables & Patents & Citations & $R \& D$ & Age & $\begin{array}{l}\text { Current } \\
\text { Tenuse }\end{array}$ & Job & $\begin{array}{l}\text { Total } \\
\text { Tenure }\end{array}$ & Gender & $\begin{array}{c}\text { Political } \\
\text { Affliation }\end{array}$ & Culture & Education & $\begin{array}{l}\text { Firm } \\
\text { Size }\end{array}$ & $\begin{array}{c}\text { Capital } \\
\text { Intensity }\end{array}$ & $\begin{array}{c}\text { Cash } \\
\text { Holding } \\
\mathrm{s}\end{array}$ & $\begin{array}{c}\text { Book } \\
\text { Leverag } \\
\mathrm{e}\end{array}$ & $\begin{array}{c}\text { Industry } \\
\text { Growth } \\
\text { Rate }\end{array}$ \\
\hline $\begin{array}{l}\text { Patents } \\
\text { Citations }\end{array}$ & $\begin{array}{l}1.000 \\
0.949 *\end{array}$ & 1.000 & & & & & & & & & & & & & & \\
\hline$R \& D$ & $0.446^{*}$ & $0.430 *$ & 1.000 & & & & & & & & & & & & & \\
\hline Age & 0.000 & -0.007 & $0.037 *$ & 1.000 & & & & & & & & & & & & \\
\hline Current Tenure & $0.067 *$ & $0.111^{*}$ & $0.043^{*}$ & -0.013 & 1.000 & & & & & & & & & & & \\
\hline Job & 0.029 & 0.019 & -0.012 & $-0.038^{*}$ & 0.012 & 1.000 & & & & & & & & & & \\
\hline Total Tenuse & $0.046^{*}$ & 0.029 & $-0.052^{*}$ & 0.004 & $-0.035^{*}$ & $0.084^{*}$ & 1.000 & & & & & & & & & \\
\hline Gender & 0.023 & $0.038^{*}$ & -0.023 & $-0.070^{*}$ & $0.037 *$ & -0.018 & 0.010 & 1.000 & & & & & & & & \\
\hline Political Affiliation & $0.071^{*}$ & $0.074^{*}$ & -0.014 & -0.024 & -0.006 & $-0.032^{*}$ & 0.027 & $0.050 *$ & 1.000 & & & & & & & \\
\hline Culture & $0.209 *$ & $0.208^{*}$ & $0.272^{*}$ & -0.027 & $0.069 *$ & 0.020 & -0.017 & $-0.033^{*}$ & -0.012 & 1.000 & & & & & & \\
\hline Education & $0.054^{*}$ & $0.050^{*}$ & $0.125^{*}$ & $-0.033^{*}$ & 0.025 & $0.031 *$ & $0.031^{*}$ & 0.028 & $0.059 *$ & $0.052^{*}$ & 1.000 & & & & & \\
\hline Firm Size & $0.109 *$ & $0.099 *$ & $-0.234^{*}$ & $-0.035^{*}$ & $0.090 *$ & $0.081^{*}$ & $0.071 *$ & $0.033^{*}$ & $0.165^{*}$ & -0.015 & $0.035 *$ & 1.000 & & & & \\
\hline Capital Intensity & $-0.178^{*}$ & $-0.185^{*}$ & $-0.156^{*}$ & $-0.068 *$ & -0.009 & $-0.073^{*}$ & $0.057 *$ & -0.021 & -0.025 & $-0.123^{*}$ & $0.045^{*}$ & $0.111^{*}$ & 1.000 & & & \\
\hline Cash Holdings & $0.332^{*}$ & $0.331 *$ & $0.540^{*}$ & 0.027 & 0.001 & -0.025 & $-0.030^{*}$ & $0.047 *$ & 0.006 & $0.198^{*}$ & $0.055^{*}$ & $-0.217^{*}$ & $-0.236 *$ & 1.000 & & \\
\hline Book Leverage & $-0.113^{*}$ & $-0.088^{*}$ & $-0.124^{*}$ & -0.022 & $0.075^{*}$ & -0.003 & -0.030 & 0.020 & -0.013 & $-0.035^{*}$ & -0.004 & $-0.039 *$ & $0.099 *$ & $-0.224^{*}$ & 1.000 & \\
\hline Industry Growth Rate & -0.011 & -0.012 & $0.036^{*}$ & $0.038^{*}$ & $-0.035^{*}$ & -0.011 & $-0.045^{*}$ & -0.017 & -0.001 & 0.020 & $-0.044^{*}$ & $-0.069 *$ & $-0.153^{*}$ & $0.055^{*}$ & -0.000 & 1.000 \\
\hline
\end{tabular}

Note: This table reports the correlations between patent citations and diversity attributes for the sample study of US firms.

\section{Empirical Results}

Table 5 presents the results on the relation between TMT diversity attributes and innovation as measured by patents and citation counts in columns 1 and 2 respectively. Estimated coefficients for current tenure are positive and significant at the 5\% level for patents and $1 \%$ level for citations. Coefficients are estimated as 0.251 and 0.864 respectively as shown in columns 1 and 2. Accordingly, this indicates a positive association between TMT members' total tenure and innovation as measured by patents and citations. Estimated coefficient on total tenure shows a value of 0.501 and significant at the $1 \%$ level as shown in column 1 . In terms of economic significance, the impact on innovation for the median firm can be estimated by taking the median of the Blau ratio of our sample and adjusting this ratio to assume the theoretical maximum diversity. This assumes that all other values are held constant at their respective median values. The tenure attribute exhibits a median Blau ratio of 0.75 in our sample. By projecting the theoretical maximum Blau ratio of 1, innovation for the median firm would be improved by $6 \%$ and $3 \%$ as measured by patents and citations respectively. As a result, the positive relationship between tenure and firm innovation supports our hypothesis.

Estimated coefficients indicate a positive relation between political affiliation and the innovation measures. As shown in columns 1 and 2, coefficients are estimated as 0.207 and 0.377 for patent and citation counts respectively, both of them significant at the $5 \%$ level. As in the case of current tenure, we can evaluate the economic significance of political affiliation diversity by examining the change in innovation if the median firm were to increase its diversity in political affiliation from the sample median to the theoretical maximum value. The political affiliation attribute shows a median Blau ratio of 0.75 . By projecting the theoretical maximum Blau ratio of 1, innovation would be improved by $2 \%$ as measured either by patents or citations. Therefore, the positive relation between political affiliation and firm innovation also supports our hypothesis.

Estimates also shows a positive relation between culture and firm innovation. Columns 1 and 2 show coefficients of 1.700 and 2.592 for patents and citation counts respectively, both of them significant at the $1 \%$ level. As a result, these positive coefficients further support our hypothesis. Following similar approach applied in the two previous diversity attributes, the economic impact of cultural diversity can be estimated by projecting the improvement in innovation output for the average firm from the median Blau ratio of 0.37 to the theoretical maximum of 1 . By doing so, innovation would be improved by $40 \%$ and $35 \%$ as measured by patents and citations respectively. The positive association between culture and firm innovation also supports our main hypothesis.

Estimates show positive coefficients for education of 0.284 based on patents and 0.444 for citations and both significant at the $10 \%$ level. Thus, this positive relation between education and firm innovation supports our hypothesis. Based on the same approach described earlier, the economic impact of education diversity can be estimated by taking the median Blau ratio of the sample, which is 0.72 and projecting the innovation improvement assuming the maximum theoretical diversity ratio of 1 . The result would be an increase of $4 \%$ and $3 \%$ in patents and citations respectively for the median firm. Remaining estimates are not significant at the $1 \%$ to $10 \%$ level. Columns 1 and 2 show mixed coefficients for age, gender and job diversity under patent and citation counts though such coefficients are not significant. Therefore, not enough evidence regarding these diversity traits is found to support our main hypothesis. 
The coefficients of the control variables selected for this study produced results consistent with prior studies. Firm size, which was proxied using total assets, shows a positive coefficient of 0.270 and 0.397 for patent and citation counts respectively and significant at the $1 \%$ level. Accordingly, this would indicate the larger the firm, the more likely it will innovate which is consistent with other studies (He \& Tian, 2013; Chang, Fu, Low \& Zhang, 2015; Sunder, Sunder \& Zhang, 2017). Likewise, coefficients for other control variables are consistent with prior literature. Across all columns of table 6 , the estimated coefficients on capital intensity are negative standing at -0.189 to -0.332 for patent and citation counts respectively and both significant at the $1 \%$ level. Column 3 and 4 shows positive association between cash holdings and firm innovation with coefficients of 4.705 and 7.528 for patents and citation counts respectively and significant at the $1 \%$ level. This finding is also consistent with Chang, Fu, Low and Zhang (2015) who reported firms with greater cash holdings are more likely to innovate as they possess more resources for investment.

Leverage show a negative association with innovative activity based on patent counts though relationship is not significant. Industry sales growth shows a negative association for patents and citation counts though relationship is significant at the $10 \%$ level for citations only. This finding supports the notion that a higher sales growth does not necessarily drive firms' innovative activity and is consistent with Yoon, Kim and Song (2016) who found pressure to innovate to be low in those industries with high growth rate.

Table 5. Relation between TMT diversity and innovation

\begin{tabular}{|c|c|c|}
\hline VARIABLES & (1) Patent & (2) Citation \\
\hline Age & $\begin{array}{l}0.0153 \\
(0.151)\end{array}$ & $\begin{array}{l}-0.119 \\
(0.239)\end{array}$ \\
\hline Current Tenure & $\begin{array}{l}0.251^{* *} \\
(0.113)\end{array}$ & $\begin{array}{c}0.864^{* * *} \\
(0.190)\end{array}$ \\
\hline Job & $\begin{array}{l}-0.0179 \\
(0.149)\end{array}$ & $\begin{array}{l}-0.0915 \\
(0.232)\end{array}$ \\
\hline Total Tenure & $\begin{array}{c}0.501^{* * *} \\
(0.187)\end{array}$ & $\begin{array}{c}0.493 \\
(0.307)\end{array}$ \\
\hline Gender & $\begin{array}{l}-0.141 \\
(0.115)\end{array}$ & $\begin{array}{l}-0.0843 \\
(0.188)\end{array}$ \\
\hline Political Affiliation & $\begin{array}{l}0.207^{* *} \\
(0.103)\end{array}$ & $\begin{array}{l}0.377^{* *} \\
(0.169)\end{array}$ \\
\hline Culture & $\begin{array}{c}1.700^{* * *} \\
(0.241)\end{array}$ & $\begin{array}{c}2.592^{* 8 *} \\
(0.411)\end{array}$ \\
\hline Education & $\begin{array}{l}0.284^{*} \\
(0.146)\end{array}$ & $\begin{array}{l}0.444^{8} \\
(0.235)\end{array}$ \\
\hline Firm Size & $\begin{array}{c}0.270^{* * *} \\
(0.0277)\end{array}$ & $\begin{array}{c}0.397^{* * *} \\
(0.0477)\end{array}$ \\
\hline Capital Intensity & $\begin{array}{c}-0.189 * * 8 \\
(0.0303)\end{array}$ & $\begin{array}{c}-0.332^{* * *} \\
(0.0372)\end{array}$ \\
\hline Cash Holdings & $\begin{array}{c}4.705^{* * *} \\
(0.298)\end{array}$ & $\begin{array}{c}7.528^{* * *} \\
(0.467)\end{array}$ \\
\hline Leverage & $\begin{array}{l}-0.103 \\
(0.228)\end{array}$ & $\begin{array}{c}0.173 \\
(0.346)\end{array}$ \\
\hline Industry Growth Rate & $\begin{array}{l}-0.385 \\
(0.291)\end{array}$ & $\begin{array}{l}-0.732^{*} \\
(0.436)\end{array}$ \\
\hline Constant & $\begin{array}{c}-2.134^{* * *} \\
(0.340)\end{array}$ & $\begin{array}{c}-2.816^{* * *} \\
(0.565)\end{array}$ \\
\hline $\begin{array}{l}\text { Observations } \\
\text { R-squared } \\
\text { Number of firms }\end{array}$ & $\begin{array}{l}2,643 \\
0.173\end{array}$ & $\begin{array}{l}2,643 \\
0.170\end{array}$ \\
\hline
\end{tabular}

Note: This table presents the results of the effect of TMT diversity attributes on patent and citation counts

\section{Conclusions}

Can diversity at the top management drive a firm's innovation? In this paper, different diversity traits exhibited by top managers and how firm's innovation is affected have been studied. Diversity attributes include age, gender, tenure, political affiliation, cultural, educational and work diversity. Firms' innovation is proxied by the count of patents granted and citations received over these patents during 2010 to 2017. Accordingly, not all diversity attributes are found to contribute to a firm's innovation. An individual's culture, tenure, educational background and political affiliation was found to be positively related to firm's innovative capability. As hypothesized in this study, a variety of top management members with different cultures, tenure, educational levels and political affiliation provide different views and perspectives along different types and levels on knowledge, which in turn results in a greater ability to solve complex problems. On the other hand, attributes, such as age, gender and work diversity were found not to be significant drivers of a firm's innovative output when other measures of diversity are included. 
Although this study included several attributes as proxies for managerial characteristics, I acknowledge this may not be perfect as the $\mathrm{R}^{2}$ for both models was at most 0.173 , which is low but consistent with closely related studies such as Mayer, et al. (2018). Managerial characteristics are based on individual differences and therefore, there could be other attributes and dimensions that are worthy to be the subject of future studies. An interesting attribute would be religious affiliation, which has not been studied thoroughly perhaps due to the difficulty on finding the data, and may provide valuable insights on what drives firm's innovative output.

Based on the findings, companies seeking to innovate must be receptive to views and perspectives that can be generated from top management members of different cultures, tenure, educational background and political affiliation. In addition, while the outcome for some diversity attributes did not come as expected, it is possible a less variety of these attributes place a greater emphasis in some industries, such as age in the technology industry. As almost $50 \%$ of the firms can be classified in the technology sector, it would be interesting to conduct further research on these industries to uncover specific managerial characteristics that drive their high level of innovation.

\section{References}

Agresti, A., \& Agresti, B. (1978). Statistical analysis of qualitative variation. Sociological Methodology, 9, 204-237. https://doi.org/10.2307/270810

Allison, P. (1978). Measures of inequality. American Sociological Review, 43, 865-880. https://doi.org/10.2307/2094626

Bantel, K., \& Jackson, S. (1989). Top management and innovations in banking: does the composition of the top team make a difference?. Strategic Management Journal, 10, 107-124. https://doi.org/10.1002/smj.4250100709

Baranchuk, N., Kieschnick, R., \& Moussawi, R. (2013). Motivating innovation in newly public firms. Journal of Financial Economics, 111, 576-588. https://doi.org/10.1016/j.jfineco.2013.11.010

Blalock, H. (1963). Correlated independent variables: the problem of multicollinearity. Social Forces, 42(2), 233-237. https://doi.org/10.2307/2575696

Blau, P. M. (1977). Inequality and heterogeneity. New York, NY: Free Press.

Brooks, C. (2014). Introductory econometrics for finance. New York, NY: Cambridge University Press. Retrieved from

http://prof.iauba.ac.ir/images/Uploaded_files/Introductory\%20Econometrics\%20for\%20Finance\%20(2014)[352 3178].PDF

Carpenter, M. (2002). The implications of strategy and social context for the relationship between top management team heterogeneity and firm performance. Strategic Management Journal, 23, 275-284. https://doi.org/10.1002/smj.226

Chang, X., Fu, K., Low, A., \& Zhang, W. (2015). Non-executive employee stock options and corporate innovation. Journal of Financial Economics, 115, 168-188. https://doi.org/10.1016/j.jfineco.2014.09.002

Chemmanur, T., Kong, L., Krishnan, K., \& Yu, Q. (2019). Top management human capital, inventor mobility, and corporate innovation. Journal of Financial and Quantitative Analysis, 0, 1-40. https://doi.org/10.1017/S0022109018001497

Custodio, C., Ferreira, M., \& Matos, P. (2019). Do general managerial skills spur innovation?. Management Science, 65(2), 459-476. https://doi.org/10.1287/mnsc.2017.2828

Daft, R. L., \& Weick, K. (1984). Toward a model of organizations as interpretation systems. Academy of Management Review, 9, 284-295. https://doi.org/10.5465/amr.1984.4277657

Faleye, O., Kovacs, T., \& Venkateswaran, A. (2014). Do better-connected CEOs innovate more? Journal of Financial and Quantitative Analysis, 49(5/6), 1201-1225. https://doi.org/10.1017/S0022109014000714

Finkelstein, S., Hambrick, D., \& Cannella, A. (2009). Strategic leadership: theory and research on executives, top management teams, and boards. Oxford, UK: Oxford United Press. https://doi.org/10.1093/acprof:oso/9780195162073.003.0005

Galasso, A., \& Simcoe, T. (2011). CEO overconfidence and innovation. Management Science, 57(8), 1469-1484. https://doi.org/10.1287/mnsc. 1110.1374

Goh, F. (2014). 10 companies that failed to innovate resulting in business failure. Enterprise Innovation. Retrieved from https://www.collectivecampus.io/blog/10-companies-that-were-too-slow-to-respond-to-change 
Griliches, Z., Pakes, A., \& Hall, B. (1988). The value of patents as indicators of inventive activity. The National Bureau of Economic Research. Retrieved from https://www.nber.org/papers/w2083

Gujarati, D. (2003). Basic econometrics. New York, NY: McGraw-Hill.

Hall, B., Jaffe, A., \& Trajtenberg, M. (2005). Market value and patent citations. The RAND Journal of Economics, 36, 16-38.

Hambrick, D., \& Mason, P. (1984). Upper echelons: the organization as a reflection of its top managers. Academy of Management, 9, 193-206. https://doi.org/10.5465/amr.1984.4277628

He, J., \& Tian, X. (2013). The dark side of analyst coverage: the case of innovation. Journal of Financial Economics, 109, 856-878. https://doi.org/10.1016/j.jfineco.2013.04.001

He, J., \& Tian, X. (2018). Finance and corporate innovation: a survey. Journal of Financial Studies, 47, 165-212. https://doi.org/10.1111/ajfs. 12208

Hewlett, S., Mashall, M., \& Sherbin, L. (2013, December). How diversity can drive innovation. Harvard Business Review, 30 .

Hirshleifer, D., Hsu, P.-H., \& Li, D. (2013). Innovative efficiency and stock returns. The Journal of Financial Economics, 107, 632-654. https://doi.org/10.1016/j.jfineco.2012.09.011

Hirshleifer, D., Low, A., \& Hong Teoh, S. (2012). Are overconfident CEOs better innovators?. The Journal of Finance, 4, 1457-1497. https://doi.org/10.1111/j.1540-6261.2012.01753.x

Joshi, A., \& Jackson, S. (2003). Managing workforce diversity to enhance cooperation in organizations. International Handbook of Organizational Teamwork and Cooperative Working. New York, NY: John Willey $\&$ Sons Ltd.

Mayer, R., Warr, R., \& Zhao, J. (2018). Do pro-diversity policies improve corporate innovation?. Financial Management, 1-34. https://doi.org/10.1111/fima.12205

Moore, D., \& Healy, P. (2008). The trouble with overconfidence. Psychological Review, 115(2), 502-517. https://doi.org/10.1037/0033-295X.115.2.502

Nathan, M., \& Lee, N. (2013). Cultural diversity, innovation, and entrepreneurship: firm-level evidence from London. Economic Geography, 89(4), 367-394. https://doi.org/10.1111/ecge.12016

Nielsen, B., \& Nielsen, S. (2013). Top management team nationality diversity and firm performance: A multilevel study. Strategic Management Journal, 34, 373-382. https://doi.org/10.1002/smj.2021

Nutt, P. C. (1984). Types of organizational decision processes. Administrative Science Quarterly, 29, 414-450. https://doi.org/10.2307/2393033

Rumsey, D. (2010). Statistics essentials. Indianapolis (IN): Wiley Publishing.

Sunder, J., Sunder, S., \& Zhang, J. (2017). Pilot CEOs and corporate innovation. Journal of Financial Economics, 123, 209-224. https://doi.org/10.1016/j.jfineco.2016.11.002

Teachman, J. (1980). Analysis of population diversity. Sociological Methods and Research, 8(3), 341-362. https://doi.org/10.1177/004912418000800305

Van de Ven, A. H., \& Diane, F. (1980). Measuring and assessing organizations. New York, NY: Wiley, New York.

Zuckerman, M. (2007). Sensation seeking and risky behavior. American Psychological Association, Washington, DC. https://doi.org/10.1037/11555-000

\section{Copyrights}

Copyright for this article is retained by the author(s), with first publication rights granted to the journal.

This is an open-access article distributed under the terms and conditions of the Creative Commons Attribution license (http://creativecommons.org/licenses/by/4.0/). 